\title{
Acceptability of COVID-19 Vaccines and Protective Behavior among Adults in Taiwan: Associations between Risk Perception and Willingness to Vaccinate against COVID-19
}

\author{
Feng-Jen Tsai ${ }^{1,2}, * \mathbb{D}$, Hsiu-Wen Yang ${ }^{2}$, Chia-Ping Lin ${ }^{1} \mathbb{D}$ and Jeffrey Zen Liu ${ }^{2} \mathbb{D}$ \\ 1 Master's Program in Global Health and Development, College of Public Health, Taipei Medical University, \\ Taipei 110, Taiwan; spadeh2294@tmu.edu.tw \\ 2 Program in Global Health and Health Security, College of Public Health, Taipei Medical University, \\ Taipei 110, Taiwan; ula0442@gmail.com (H.-W.Y.); d537108008@tmu.edu.tw (J.Z.L.) \\ * Correspondence: jeanfjtsai@tmu.edu.tw; Tel.: +886-2-6638-2736 (ext. 1282)
}

check for updates

Citation: Tsai, F.-J.; Yang, H.-W.; Lin, C.-P.; Liu, J.Z. Acceptability of COVID-19 Vaccines and Protective Behavior among Adults in Taiwan: Associations between Risk Perception and Willingness to Vaccinate against COVID-19. Int. J. Environ. Res. Public Health 2021, 18, 5579. https:// doi.org/10.3390/ijerph18115579

Academic Editor: Paul B. Tchounwou

Received: 16 March 2021

Accepted: 19 May 2021

Published: 23 May 2021

Publisher's Note: MDPI stays neutral with regard to jurisdictional claims in published maps and institutional affiliations.

Copyright: (c) 2021 by the authors. Licensee MDPI, Basel, Switzerland. This article is an open access article distributed under the terms and conditions of the Creative Commons Attribution (CC BY) license (https:/ / creativecommons.org/licenses/by/ $4.0 /)$.

\begin{abstract}
This study aims to evaluate acceptance of COVID-19 vaccines and the impact of risk perception on vaccine acceptance and personal health protective behaviors in Taiwan. A nationwide cross-sectional study was conducted from 19 to 30 October 2020; 1020 participants were included in the final analysis; chi-square and logistic regression analyses were conducted. In total, $52.7 \%$ of participants were willing to receive COVID-19 vaccines, $63.5 \%$ perceived the severity of COVID-19 in Taiwan as "not serious", and nearly 40\% were worried about COVID-19 infection. Participants with higher perceived severity of COVID-19 had significantly higher odds of refusing the vaccine $(\mathrm{OR}=1.546)$, while those worried about infection had lower odds of poor health protective behaviors $(\mathrm{OR}=0.685)$. Vaccine refusal reasons included "the EUA process is not strict enough" $(48.7 \%)$ and "side effects" (30.3\%). Those who had previously refused other vaccinations were 2.44 times more likely to refuse the COVID-19 vaccines. Participants' age had an influence on COVID-19 vaccine acceptance. In general, the Taiwanese public's acceptance of the vaccine was lower than that in other high-income countries. Elderly participants and those with college-level education and above who had previously refused vaccines had lower willingness to receive a COVID-19 vaccine. Risk perception was positively associated with personal health protective behaviors but negatively associated with COVID-19 vaccine acceptance.
\end{abstract}

Keywords: vaccine; COVID-19; risk perception; willingness; Taiwan

\section{Introduction}

The World Health Organization (WHO) declared the coronavirus disease 2019 (COVID19) a Public Health Emergency of International Concern (PHEIC) on 30 January 2020 [1]. As of January 2021, there were more than 110 million cases and 2.4 million deaths worldwide due to COVID-19 [2]. Compared with other countries, Taiwan was not seriously affected by the COVID-19 pandemic in 2020. On 21 January 2020, Taiwan reported its first confirmed imported case of 2019-nCoV, leading to the Taiwan Centers for Disease Control (TCDC) establishing the Central Epidemic Command Center (CECC) with inter-departmental horizontal coordination involving the Ministries of the Interior, Education, Transportation and Communications, etc. [3,4].

Based on its previous experience from the SARS outbreak, the Taiwanese government took prompt and effective action to mitigate and control COVID-19 within the country. As of May 2021, Taiwan has had 1145 confirmed cases and 12 deaths, with a majority of cases being imported [5]. This controlled outbreak has led to Taiwan being listed as one of the countries with moderate economic impact as its gross domestic product (GDP) declined by less than $1 \%$ [6].

Taiwan has effectively mitigated the effects of COVID-19 through border management, health inspections, contact tracing, and other public health measures [7]. However, vaccines 
are still listed as one of the prioritized strategies for achieving herd immunity for further policy movement [8]. Taiwan has purchased a large number of vaccines and aims to begin a large-scale vaccination program in the following months [9]. According to the WHO Strategic Expert Advisory Group (SAGE) and the Global Vaccine Safety Advisory Committee (GACVS), one of the goals of the COVID-19 vaccine communication plan is to achieve high acceptance and uptake [10]. The current acceptance of COVID-19 vaccines globally is approximately $35 \%$ to $98 \%$, which varies greatly from country to country, further indicating the need for policymakers to understand public perceptions before large-scale vaccination [11-13]. This study was conducted to fill the information gap regarding this issue in Taiwan.

The perception of the severity of the COVID-19 pandemic is related to people's awareness of risks and encourages the public to further participate in disease prevention measures $[14,15]$. This can also be verified as it is related to vaccinations during the H1N1 influenza pandemic and the subsequent formulation of prevention policies, corresponding to the theoretical structure of threat and response assessments in the use of the individual healthy behavior models [16-18]. When the public's perception of the severity of COVID-19 is higher, the willingness to implement preventative measures is higher [19-21]. Previous studies based on this theory showed that perceived severity of COVID-19 and the fear of contracting COVID-19 were positively associated with vaccine acceptance [22]. In addition, higher levels of risk exposure and negative attitudes toward general vaccination were associated with low vaccine acceptance [23]. Since the COVID-19 pandemic is not severe in Taiwan, the authors wondered about whether the impact of risk perception on vaccine acceptance is still sustained in Taiwan. Therefore, we conducted this national survey to evaluate the impact of risk perception on public acceptance regarding COVID-19 vaccines and the factors influencing willingness to vaccinate in Taiwan. In addition, we investigated the impact of risk perception on recommended personal health protective behavior, such as handwashing, mask wearing, and social distancing. Although vaccines and practicing personal health protective behaviors are measures recommended by the government, the decision-making process for vaccination is complicated and potentially affected by a variety of factors such as trust in the government, historical influences, and religion [24,25]. This study looks into the impact of risk perception on practicing personal health protective behavior and how it differs from its impact on vaccination acceptance.

Therefore, the aims of this study are to (1) understand public acceptance of COVID19 vaccines in Taiwan and influencing factors; (2) evaluate the association between risk perception and public acceptance of COVID-19 vaccines; and (3) evaluate the association between risk perception and personal health protective behaviors.

\section{Materials and Methods}

\subsection{Research Design}

The cross-sectional study was conducted from 19 to 30 October 2020. Participants were adults aged over 20, fluent in Mandarin and/or Taiwanese, who lived in Taiwan.

Data were collected by an academic institution's public opinion polling center through an anonymous national telephone survey with structured questionnaire interviews. Stratified sampling was used during the survey period. A total of 14,866 random telephone calls to respondents from different counties and cities across the nation were made, with 1077 respondents completing the survey-a response rate of $7.24 \%$. Those who responded to the telephone survey did not receive any incentive. Further weighting was applied in order to maintain full representation of the country's population. Participants' individual characteristics, including age, gender, education, religion, and work status were also collected. In total, 1020 participants were included in the final analysis after excluding participants who did not respond regarding their willingness to receive a COVID-19 vaccine. The analytic sample was not different from the 1077 participants who took the survey. 


\subsection{Measures}

The research team developed the questionnaire to examine risk perception and willingness to vaccinate against COVID-19 among Taiwan's population based on a 2014 national survey [26]. The questionnaire was then reviewed by a panel of experts with backgrounds in anthropology, immunology, law, medicine, public health, and sociology. Revisions were made based on the expert panel's comments. The revised questionnaire was further pilot-tested with 15 adults.

The questionnaire used in this research includes six dimensions: "sources of vaccine information", "factors affecting willingness to vaccinate", "attitude toward different vaccine resource allocation ethical approach", and "risk perception, willingness to vaccinate, and health behaviors regarding COVID-19 in Taiwan". This study specifically analyzed the parts of "factors affecting willingness to vaccinate" and "risk perception, willingness to vaccinate, and personal health protective behaviors regarding COVID-19 in Taiwan".

\subsubsection{Risk Perception, Vaccine Knowledge, and Previous Experience with Vaccination}

Participants' risk perception regarding COVID-19 in Taiwan was evaluated using two questions: "What do you think of the severity of the COVID-19 outbreak in Taiwan?" and "To what level do you worry about getting COVID-19?" Responses were based on a 5-point Likert scale, ranging from "very serious" to "not very serious" and from "very worried" to "not very worried".

Participants' perceptions of their knowledge regarding vaccines were assessed using a self-evaluated question: "Please rate your understanding regarding vaccines from 1 (lowest) to 10 (highest)". Participants' previous experience with vaccinations was assessed with the following question: "Have you ever refused a vaccination while it is recommended by the government for yourself and your kids?"

\subsubsection{Willingness to Vaccinate and Personal Health Protective Behaviors Regarding COVID-19}

Participants' vaccine acceptance was assessed using the following question: "Are you willing to get a COVID-19 vaccine if the vaccine is provided through the Emergency Use Authorization (EUA) process for approval?" Responses included "I am willing to get the COVID 19 vaccine" and "I am not willing to get the COVID 19 vaccine"; their reasons as to why they were not willing to receive a COVID-19 vaccine were collected for further analysis.

Participants' personal health protective behaviors were assessed with 3 questions: "Do you agree with the statement: 'I wash my hands more frequently compared to before the COVID-19 pandemic'"; "Do you agree with the statement: 'I wear masks more frequently compared to before the COVID-19 pandemic', and "In the past 30 days, how carefully have you maintained social distancing (1.5 $\mathrm{m}$ indoors and 1-m outdoors)?" Responses were based on a 5-point Likert scale, ranging from "strongly agree" to "strongly disagree" and from "always" to "never".

\subsection{Statistical Analysis}

A Chi-square test was used to compare individual characteristics, including sex, age, education, religion, occupational status, and willingness to vaccinate against COVID-19, as well as "self-rated vaccine knowledge", "experience of vaccine refusal", "severity of the COVID-19 pandemic in Taiwan", and "concern about contracting COVID-19" between participants willing and unwilling to receive a COVID-19 vaccine.

The 5-point Likert scale of the three personal health protective behaviors (handwashing, masks wearing, and keeping social distancing) was summarized as the overall indicator of "Health Protective Behavior", which was further classified for further analysis into the "Good behavior" and "Poor behavior" groups via the median score. The health protective behavior data skewed left. There are two reasons to combine all "health protective behaviors" into one single measure. First, all three health protective behaviors were rec- 
ommended by the Taiwan CDC, and adopting all three health protective behaviors could protect individuals from the risk of contracting COVID-19. Second, participants' responses regarding behaviors such as handwashing and wearing masks were comparatively high, so we combined them to achieve better grouping of participants into good and poor health behavior groups.

Participants' perceived knowledge of vaccines was categorized into three groups"low", "medium", and "high"-for analysis in our study due to concerns that the data were not normally distributed.

Regression analysis was then applied to determine the correlation between willingness to receive a COVID-19 vaccine and risk perception. Bivariate analysis was initially used to understand the relationship between willingness to receive COVID-19 vaccination and potential confounding factors including age, sex, education, religion, occupational status, self-rated vaccine knowledge, and experience of vaccine refusal. Logistic regression was then applied to determine the statistical significance of the association between participants' willingness to receive COVID-19 vaccination and their risk perception. This approach was also applied to understand the association between participants' health protective behaviors and their risk perception. Our study's dependent variables are "unwillingness to take COVID-19 vaccination" and" poor health protective behaviors in COVID-19 prevention", while the independent variables are "severity of COVID-19 pandemic in Taiwan" and "concern regarding COVID-19 infection". Individual characteristics including sex, education, age, occupational status, and experience of vaccine refusal are covariates of interest.

The odds ratios (ORs) and 95\% confidence intervals (CIs) were also calculated, and the significance level was set at 0.05 . All statistical analyses were conducted in SPSS version 18 (IBM, Armonk, NY, USA).

\section{Results}

\subsection{Individual Characteristics of Participants}

The individual characteristics of participants are provided in Table 1. Among 1020 participants, the majority were women $(56.7 \%)$, and the age group with the highest proportion $(43.7 \%)$ were $40-59$ years old. Coupled with participants above 60 years old, the proportion of participants over 40 years old in the entire survey was $77.3 \%$. In total, $54.8 \%$ of participants had undergraduate degrees or higher, and $61.3 \%$ of them were currently employed. Approximately one third of participants stated that they had no religious beliefs (36.0\%).

Regarding willingness to receive a COVID 19 vaccine, $52.7 \%$ of participants were willing to receive the vaccine, while nearly half $(47.3 \%)$ were unwilling to receive it. The main reason for refusing the vaccine was concern that "the EUA process is not strict enough" (296/608, 48.7\%), followed by concern regarding "side effects" (184/608, 30.3\%). All of the options and responses regarding participants' vaccine refusal are provided in the Supplementary Materials.

Chi-square analysis showed that sex, education, and occupational status were all significantly different between the "willing and unwilling to take COVID-19 vaccine" groups. There were significantly more female participants in the unwilling group. The percentage of participants with undergraduate degrees or higher and the percentage of participants that were currently employed were both significantly higher among participants who were not willing to receive a COVID-19 vaccine.

Within each individual factor, the percentage of participants unwilling to receive a COVID-19 vaccine is higher among women (50.17\%) than among men (43.44\%) and higher among those who were employed (49.76\%) than those unemployed/retired (43.08\%). Regarding religion, the percentage of participants unwilling to receive a COVID-19 vaccine is highest among Christians (52.83\%), but the difference is not significant. 
Table 1. Basic demographic characteristics affecting COVID-19 vaccine uptake intention.

\begin{tabular}{|c|c|c|c|c|c|c|c|}
\hline \multirow{2}{*}{ Variables } & \multicolumn{2}{|c|}{$\begin{array}{c}\text { Total } \\
(n=1020)\end{array}$} & \multicolumn{2}{|c|}{$\begin{array}{l}\text { Unwilling } \\
(n=482)\end{array}$} & \multicolumn{2}{|c|}{$\begin{array}{l}\text { Willing } \\
(n=538)\end{array}$} & \multirow{2}{*}{$p$-Value } \\
\hline & $n$ & $\%$ & $n$ & $\%$ & $n$ & $\%$ & \\
\hline \multicolumn{8}{|l|}{$\operatorname{Sex}(n=1020)$} \\
\hline Male & 442 & $43.3 \%$ & 192 & $39.8 \%$ & 250 & $46.5 \%$ & 0.033 \\
\hline Female & 578 & $56.7 \%$ & 290 & $60.2 \%$ & 288 & $53.5 \%$ & \\
\hline \multicolumn{8}{|l|}{ Education $(n=1014)$} \\
\hline High school and below & 458 & $45.2 \%$ & 176 & $36.8 \%$ & 282 & $52.6 \%$ & $<0.001$ \\
\hline College & 479 & $47.2 \%$ & 259 & $54.2 \%$ & 220 & $41.0 \%$ & \\
\hline Master and above & 77 & $7.6 \%$ & 43 & $9.0 \%$ & 34 & $6.3 \%$ & \\
\hline \multicolumn{8}{|l|}{ Age groups $(n=1020)$} \\
\hline $20 \sim 39$ & 187 & $17.4 \%$ & 83 & $17.2 \%$ & 104 & $19.3 \%$ & 0.238 \\
\hline $40 \sim 59$ & 471 & $43.7 \%$ & 236 & $49.0 \%$ & 235 & $43.7 \%$ & \\
\hline Above 60 (including) & 362 & $33.6 \%$ & 163 & $33.8 \%$ & 199 & $37.0 \%$ & \\
\hline \multicolumn{8}{|l|}{ Religion $(n=1016)$} \\
\hline $\begin{array}{l}\text { Folk religion (including Taoism } \\
\text { and Yiguandao) }\end{array}$ & 291 & $28.6 \%$ & 127 & $26.5 \%$ & 164 & $30.5 \%$ & 0.326 \\
\hline Christianity & 53 & $5.2 \%$ & 28 & $5.8 \%$ & 25 & $4.7 \%$ & \\
\hline Buddhism & 306 & $30.1 \%$ & 141 & $29.4 \%$ & 165 & $30.7 \%$ & \\
\hline No religion & 366 & $36.0 \%$ & 183 & $38.2 \%$ & 183 & $34.1 \%$ & \\
\hline \multicolumn{8}{|l|}{ Occupational status $(n=1007)$} \\
\hline Employed & 617 & $61.3 \%$ & 307 & $64.6 \%$ & 310 & $58.3 \%$ & 0.039 \\
\hline Unemployed/retired & 390 & $38.7 \%$ & 168 & $35.4 \%$ & 222 & $41.7 \%$ & \\
\hline
\end{tabular}

3.2. Comparison of Risk Perception and Factors Influencing Vaccination Willingness between Willing and Unwilling to Receive COVID-19 Vaccine Group

Comparisons of risk perception, knowledge, and experience of vaccine refusal between the willing and unwilling to receive a COVID-19 vaccine groups are shown in Table 2. Overall, more than $70 \%$ of participants self-rated their perception of their knowledge regarding vaccines as medium to high, and $28.6 \%$ of them have previously refused vaccinations for themselves. Regarding risk perception, around $63.5 \%$ of participants perceived the spread of the COVID-19 pandemic in Taiwan as "not serious", and nearly $40 \%$ responded that they were "not worried" about COVID-19 infection.

Participants' experience with refusing previous vaccines and their perception of the severity of the COVID-19 pandemic in Taiwan were both significantly different between the willing and unwilling to receive a COVID-19 vaccine groups. The percentage of participants with experience of vaccine refusal was significantly higher in the unwilling group (39.3\% in the unwilling group vs. $19.1 \%$ in the willing group), but the percentage of participants who perceived the COVID-19 pandemic in Taiwan as serious was also significantly higher in the unwilling group (17.1\% in the unwilling group vs. $11.6 \%$ in the willing group).

Table 2. Knowledge and experience of vaccination and risk perception variables affecting COVID-19 vaccine uptake intention.

\begin{tabular}{|c|c|c|c|c|c|c|c|}
\hline \multirow{2}{*}{ Variables } & \multicolumn{2}{|c|}{ Total $(n=1020)$} & \multicolumn{2}{|c|}{ Unwilling $(n=482)$} & \multicolumn{2}{|c|}{ Willing $(n=538)$} & \multirow{2}{*}{$p$-Value } \\
\hline & $n$ & $\%$ & $n$ & $\%$ & $b$ & $\%$ & \\
\hline \multicolumn{8}{|l|}{ Knowledge $(n=1020)$} \\
\hline High scores (7-10) & 346 & $33.9 \%$ & 155 & $32.2 \%$ & 191 & $35.5 \%$ & 0.497 \\
\hline Medium scores (5-6) & 391 & $38.3 \%$ & 192 & $39.8 \%$ & 199 & $37.0 \%$ & \\
\hline Low scores (1-4) & 283 & $27.7 \%$ & 135 & $28.0 \%$ & 148 & $27.5 \%$ & \\
\hline
\end{tabular}


Table 2. Cont.

\begin{tabular}{|c|c|c|c|c|c|c|c|}
\hline \multirow{2}{*}{ Variables } & \multicolumn{2}{|c|}{ Total $(n=1020)$} & \multicolumn{2}{|c|}{ Unwilling $(n=482)$} & \multicolumn{2}{|c|}{ Willing $(n=538)$} & \multirow{2}{*}{$p$-Value } \\
\hline & $n$ & $\%$ & $n$ & $\%$ & $b$ & $\%$ & \\
\hline \multicolumn{8}{|l|}{$\begin{array}{l}\text { Experience of vaccine refusal } \\
(n=1010)\end{array}$} \\
\hline Ever & 289 & $28.6 \%$ & 187 & $39.3 \%$ & 102 & $19.1 \%$ & $<0.001$ \\
\hline None & 721 & $71.4 \%$ & 289 & $60.7 \%$ & 432 & $80.9 \%$ & \\
\hline \multicolumn{8}{|l|}{$\begin{array}{l}\text { Severity of the COVID-19 } \\
\text { pandemic in Taiwan }(n=1002)\end{array}$} \\
\hline Serious & 142 & $14.2 \%$ & 81 & $17.1 \%$ & 61 & $11.6 \%$ & 0.046 \\
\hline Not serious/slightly serious & 224 & $22.4 \%$ & 102 & $21.5 \%$ & 122 & $23.1 \%$ & \\
\hline Not serious & 636 & $63.5 \%$ & 292 & $61.5 \%$ & 344 & $65.3 \%$ & \\
\hline \multicolumn{8}{|l|}{$\begin{array}{l}\text { Worried about contracting } \\
\text { COVID-19 }(n=1017)\end{array}$} \\
\hline Worried & 638 & $62.7 \%$ & 298 & $61.8 \%$ & 340 & $63.6 \%$ & 0.570 \\
\hline Not worried & 379 & $37.3 \%$ & 184 & $38.2 \%$ & 195 & $36.4 \%$ & \\
\hline
\end{tabular}

3.3. Association between Participants' Willingness to Receive COVID-19 Vaccine and Their Risk Perception

Logistic regression analysis showed that participants' sex, education, age, occupational status, experience of vaccine refusal, and perceived severity of the COVID-19 pandemic in Taiwan were significantly associated with their willingness to receive COVID-19 vaccination (Table 3). Participants who were women, had higher education levels, and were currently employed were more unwilling to receive a COVID 19 vaccine. In addition, participants aged 60 and above had ORs of 1.967 for unwillingness to receive a COVID-19 vaccine, while participants aged between 40 to 59 years old also had significantly higher ORs of unwillingness to receive a COVID-19 vaccine than participants aged less than 40 years old.

Participants who perceived the COVID-19 pandemic in Taiwan as "serious" had significantly higher odds of unwillingness to receive a COVID-19 vaccine. Participants who had previously refused vaccinations had ORs of 2.435 for refusal to receive a COVID-19 vaccine, compared to those who had never refused to receive vaccines.

\subsection{Association between Participants' Health Protective Behaviors and Their Risk Perception}

More than $90 \%$ of participants increased their frequency of handwashing and mask wearing behaviors in the previous month, and more than $70 \%$ of participants practiced social distancing to prevent COVID-19 infection.

The association between participants' health protective behaviors and their risk perception is shown in Table 4. From the analysis, participants' sex and the status of feeling worried about contracting COVID-19 were significantly associated with personal health protective behaviors.

Female participants had fewer odds of not adopting health protective behaviors than male participants $(\mathrm{OR}=0.737)$, and participants who worried about COVID-19 infection had lower odds of poor health protective behaviors $(\mathrm{OR}=0.685)$.

In addition, further analysis showed that there were more participants with poor health protective behaviors in the group of participants unwilling to receive a COVID-19 vaccine (data not shown). 
Table 3. Logistic regression model of unwillingness to receive COVID-19 vaccination.

\begin{tabular}{|c|c|c|c|c|}
\hline \multicolumn{5}{|c|}{ Estimated Odds Ratios of Unwillingness to Receive COVID-19 Vaccination } \\
\hline Variables & Crude OR $(95 \%$ CI $)$ & p-Value & Adjusted OR (95\% CI) & p-Value \\
\hline \multicolumn{5}{|l|}{ Sex } \\
\hline Male & (ref) & & (ref) & \\
\hline Female & $1.311(1.022-1.682)$ & 0.033 & $1.344(1.016-1.779)$ & 0.039 \\
\hline \multicolumn{5}{|l|}{ Education } \\
\hline High school and below & (ref) & & (ref) & \\
\hline College & $1.866(1.454-2.447)$ & $<0.001$ & $2.100(1.550-2.844)$ & $<0.001$ \\
\hline Master and above & $2.026(1.244-3.300)$ & 0.005 & $2.399(1.396-4.123)$ & 0.002 \\
\hline \multicolumn{5}{|l|}{ Age groups } \\
\hline $20 \sim 39$ & (ref) & & (ref) & \\
\hline $40 \sim 59$ & $1.258(0.895-1.769)$ & 0.186 & $1.667(1.145-2.427)$ & 0.008 \\
\hline Above 60 (including) & $1.026(0.720-1.464)$ & 0.886 & $1.967(1.254-3.086)$ & 0.003 \\
\hline \multicolumn{5}{|l|}{ Occupational status } \\
\hline Unemployed/retired & (ref) & & (ref) & \\
\hline Employed & $1.309(1.014-1.689)$ & 0.039 & $1.442(1.056-1.970)$ & 0.021 \\
\hline \multicolumn{5}{|l|}{ Experience of vaccine refusal } \\
\hline None & (ref) & & (ref) & \\
\hline Ever & $2.740(2.064-3.639)$ & $<0.001$ & $2.435(1.806-3.282)$ & $<0.001$ \\
\hline \multicolumn{5}{|l|}{$\begin{array}{l}\text { Severity of the COVID-19 } \\
\text { pandemic in Taiwan }\end{array}$} \\
\hline Not serious & (ref) & & (ref) & \\
\hline Not serious/slightly serious & $0.985(0.726-1.337)$ & 0.923 & $1.042(0.751-1.445)$ & 0.806 \\
\hline Serious & $1.564(1.084-2.258)$ & 0.017 & $1.546(1.031-2.320)$ & 0.035 \\
\hline \multicolumn{5}{|l|}{ Worried about contracting } \\
\hline \multicolumn{5}{|l|}{ COVID-19 } \\
\hline Not worried & (ref) & & (ref) & \\
\hline Worried & $0.929(0.720-1.198)$ & 0.570 & $0.795(0.601-1.053)$ & 0.110 \\
\hline
\end{tabular}

Table 4. Logistic regression model of poor health protective behaviors for COVID-19 prevention.

\begin{tabular}{|c|c|c|c|c|}
\hline \multicolumn{5}{|c|}{ Estimated Odds Ratios of Poor Health Protective Behaviors for COVID-19 Prevention } \\
\hline Variables & Crude OR $(95 \%$ CI $)$ & $p$-Value & Adjusted OR (95\% CI) & p-Value \\
\hline \multicolumn{5}{|l|}{ Sex } \\
\hline Male & (ref) & & (ref) & \\
\hline Female & $0.694(0.540-0.892)$ & 0.004 & $0.737(0.564-0.964)$ & 0.026 \\
\hline \multicolumn{5}{|l|}{ Education } \\
\hline High school and below & (ref) & & (ref) & \\
\hline College & $0.843(0.652-1.091)$ & 0.195 & $0.775(0.580-1.037)$ & 0.086 \\
\hline Master and above & $1.023(0.629-1.664)$ & 0.927 & $0.937(0.555-1.583)$ & 0.809 \\
\hline \multicolumn{5}{|l|}{ Age groups } \\
\hline $20 \sim 39$ & (ref) & & (ref) & \\
\hline $40 \sim 59$ & $0.900(0.640-1.266)$ & 0.545 & $0.861(0.599-1.238)$ & 0.420 \\
\hline Above 60 (including) & $0.872(0.612-1.244)$ & 0.451 & $0.810(0.526-1.246)$ & 0.337 \\
\hline \multicolumn{5}{|l|}{ Occupational status } \\
\hline Unemployed/retired & (ref) & & (ref) & \\
\hline Employed & $1.207(0.935-1.557)$ & 0.149 & $1.082(0.806-1.466)$ & 0.583 \\
\hline
\end{tabular}


Table 4. Cont.

\begin{tabular}{|c|c|c|c|c|}
\hline \multicolumn{5}{|c|}{ Estimated Odds Ratios of Poor Health Protective Behaviors for COVID-19 Prevention } \\
\hline Variables & Crude OR $(95 \%$ CI $)$ & p-Value & Adjusted OR (95\% CI) & p-Value \\
\hline \multicolumn{5}{|l|}{$\begin{array}{l}\text { Severity of the COVID-19 } \\
\text { pandemic in Taiwan }\end{array}$} \\
\hline Not serious & (ref) & & (ref) & \\
\hline Not serious/slightly serious & $1.116(0.820-1.519)$ & 0.485 & $1.195(0.870-1.641)$ & 0.272 \\
\hline Serious & $0.718(0.498-1.035)$ & 0.075 & $0.842(0.573-1.238)$ & 0.382 \\
\hline \multicolumn{5}{|l|}{ Worried about contracting } \\
\hline Not worried & (ref) & & (ref) & \\
\hline Worried & $0.650(0.502-0.842)$ & 0.001 & $0.685(0.522-0.900)$ & 0.007 \\
\hline
\end{tabular}

\section{Discussion}

This is the first study aimed at evaluating the acceptance of COVID-19 vaccines in Taiwan. Furthermore, this study was used to determine the impact of risk perception on both vaccine acceptance and health protective behaviors. Nearly half of the participants were unwilling to receive a COVID-19 vaccine (willing vs. unwilling: $52.7 \%$ vs. $47.3 \%$ ). Participants who were worried about COVID-19 infection were more willing to adopt health protective behaviors, but participants who perceived the risk of the COVID-19 pandemic in Taiwan to be serious were less willing to receive a COVID-19 vaccine. Moreover, willingness to accept the new vaccine is affected by past experiences, as participants who had previously refused vaccines were more likely to be unwilling to receive a COVID-19 vaccine.

Taiwan's acceptance rate of COVID-19 vaccines is lower than those of most countries around the world and lower than those of France and Sweden in particular, which already have low acceptance rates. This phenomenon might be due to the low number of cases of COVID-19 in Taiwan. The fact that vaccine coverage rates are generally over $90 \%$ in Taiwan further indicates the impact of distrust of the government as a potential explanation for our findings, similar to other countries. The main reasons that participants were unwilling to receive a COVID-19 vaccine were "the EUA (Emergency Use Authorization) process is not strict enough" and "side effects" of the vaccine, displaying a distrust of governmental control of vaccine safety and quality through the EUA process.

Surprisingly, the study results showed that participants who perceived the risk of the COVID-19 pandemic in Taiwan to be serious were less willing to receive a COVID19 vaccine. The possible explanation for this unexpected phenomenon might be the participants' sensitivity toward these issues. Participants who perceived the risk of the COVID-19 pandemic in Taiwan to be "serious" might be individuals who are more sensitive to health-related issues. These participants may be more hesitant to accept the vaccine since the COVID-19 vaccines available are comparatively new, with high uncertainty in regard to possible side effects. Further studies are needed to understand this phenomenon.

According to the $\mathrm{WHO}$, people over 60 years old are at high risk of severe COVID-19 infection [27]. Although the WHO SAGE did not consider age to be a priority for vaccine distribution, it declared that vulnerability to COVID-19 should be considered for vaccine allocation [28]. In previous studies, willingness to receive vaccines in high-risk groups, such as older adults, patients with chronic respiratory diseases, and frontline medical personnel, was found to be relatively high $[29,30]$. However, in our survey, participants aged 60 years and above had ORs of 2.00 of unwillingness to receive a COVID-19 vaccine, and participants aged between 40 and 59 years also had significantly higher ORs for unwillingness to receive a COVID-19 vaccine compared to participants aged less than 40 years. This finding indicates the need to further understand the practical considerations of this age group through in-depth interview research in the future.

In addition, we found that the impact of sociodemographic backgrounds in Taiwan was different compared to that of other countries. Previous studies in other countries 
showed that populations with higher education levels had higher willingness to receive the vaccine; however, this study's findings identified the reverse pattern [31-35]. This might be due to distrust of the government by participants with higher education levels, indicating the need for the government to develop effective communication strategies for COVID-19 vaccination for the population.

Participants who worried about COVID-19 infection were more willing to adopt health protective behaviors, but participants who perceived the risk of the COVID-19 pandemic in Taiwan to be serious were less willing to receive a COVID-19 vaccine. This indicates the different aspects that participants must consider when adopting personal health protective measures against unknown diseases such as COVID-19. Participants with a higher risk perception of COVID-19 adopted more non-invasive personal health protective behaviors, such as handwashing, mask wearing, and social distancing, but showed less willingness to receive a COVID-19 vaccine. One of the possible explanations of this phenomenon might be that partaking in non-invasive health protective behaviors only mildly inconveniences the user, unlike the potentially serious side effects of vaccination. Therefore, the impact of risk perception on vaccine acceptance and health protective behaviors is different in our study. The research results echoed the findings and argument that "the public trust in the government is the key to vaccine acceptance" [12,36,37]. Further studies are needed to understand the reason for this phenomenon.

\section{Limitations}

This study had several limitations. First, due to the use of home telephone interviews from 6.00 p.m. to 10.00 p.m. on weekdays, our participants were mainly in the middle-aged group and above. Second, the investigation period was the month of October 2020, when there was less information regarding COVID-19 vaccines than there is now. However, the findings still reflect the need to develop an effective communication strategy for vaccine acceptance in Taiwan. Third, the relationships can only be considered to be associations rather than causal due to the nature of cross-sectional design; we might also not be able to rule out reporting bias due to the data collection method. Fourth, it should be noted that the low response rate in the telephone survey may cause sample bias and overestimation results, and acceptance of COVID-19 vaccines in the real world may be lower.

\section{Conclusions}

Our findings indicate that Taiwan's vaccine acceptance was relatively low and affected by previous vaccination experiences. Elderly participants, women, and those with higher education levels were less willing to receive a COVID-19 vaccine, and participants with a higher risk perception of COVID-19 adopted more non-invasive personal health protective behaviors, such as handwashing, mask wearing, and social distancing, but showed less willingness to receive a COVID-19 vaccine. We suggest that in-depth inquiries should be conducted regarding the considerations of specific ethnic groups who refuse to receive a COVID-19 vaccine, and risk communication strategies should be developed.

Supplementary Materials: The following are available online at https: / www.mdpi.com/article/ 10.3390/ijerph18115579/s1, Table S1: Reasons for Unwillingness to Take COVID-19 Vaccination, Table S2: Reasons for Previously Refusing Vaccines.

Author Contributions: Conceptualization of study design, F.-J.T.; data collection, F.-J.T., H.-W.Y., and J.Z.L.; statistical analysis, C.-P.L.; drafting the manuscript, F.-J.T., H.-W.Y., and J.Z.L. All authors have read and agreed to the published version of the manuscript.

Funding: This work was supported by the Ministry of Science and Technology, Grant No. 108-2410H-038-013-MY3.

Institutional Review Board Statement: The study was conducted according to the guidelines of the Declaration of Helsinki and approved by the Institutional Review Board of Taipei Medical University (TMU-JIRB \#N202009025, 6 October 2020). 
Informed Consent Statement: Informed consent was obtained from all subjects involved in the study.

Data Availability Statement: The data presented in this study are available on request from the corresponding author.

Acknowledgments: The authors are grateful to the participants of this study.

Conflicts of Interest: The authors declare no conflict of interest.

\section{References}

1. WHO Statement on the Second Meeting of the International Health Regulations (2005) Emergency Committee Regarding the outbreak of Novel Coronavirus (2019-nCoV). Available online: https:/ / www.who.int/news/item/30-01-2020-statement-onthe-second-meeting-of-the-international-health-regulations-(2005)-emergency-committee-regarding-the-outbreak-of-novelcoronavirus-(2019-ncov) (accessed on 1 March 2021).

2. Johns Hopkins University COVID-19 Map-Johns Hopkins Coronavirus Resource Center. Available online: https: / coronavirus. jhu.edu/map.html (accessed on 19 February 2021).

3. Taiwan Centers for Disease Control Taiwan Timely Identifies First Imported Case of 2019 Novel Coronavirus Infection RETURNING from Wuhan, China through Onboard Quarantine; Central Epidemic Command Center (CECC) Raises Travel Notice Level for Wuhan, China to Level 3: Warning. Available online: https:/ /www.cdc.gov.tw/En/Category/ListContent/tov1jahKUv8 RGSbvmzLwFg? uaid=pVg_jRVvtHhp94C6GShRkQ (accessed on 19 February 2021).

4. Wang, C.J.; Ng, C.Y.; Brook, R.H. Response to COVID-19 in Taiwan: Big data analytics, new technology, and proactive testing. JAMA J. Am. Med. Assoc. 2020, 323, 1341-1342. [CrossRef] [PubMed]

5. Taiwan Centers for Disease Control CECC Confirms 1 More Imported COVID-19 Case; Indonesian Man Found to Have COVID19 before End of Quarantine Period. Available online: https://www.cdc.gov.tw/En/Category/ListContent/tov1jahKUv8 RGSbvmzLwFg?uaid=ualy0OtBmXRIvi9zidPbFg (accessed on 19 February 2021).

6. Our World in Data Which Countries Have Protected Both Health and the Economy in the pandemic? Available online: https: / / ourworldindata.org/covid-health-economy (accessed on 19 February 2021).

7. Summers, D.J.; Cheng, D.H.-Y.; Lin, P.H.-H.; Barnard, D.L.T.; Kvalsvig, D.A.; Wilson, P.N.; Baker, P.M.G. Potential Lessons from the Taiwan and New Zealand Health Responses to the COVID-19 Pandemic. Lancet Reg. Health West. Pacific 2020. [CrossRef]

8. Schaffer Deroo, S.; Pudalov, N.J.; Fu, L.Y. Planning for a COVID-19 Vaccination Program. JAMA J. Am. Med. Assoc. 2020, 323, 2458-2459. [CrossRef]

9. Taiwan Centers for Disease Control CECC is in Talks with Vaccine Suppliers to Purchase nearly 20 million Doses of COVID-19 Vaccines and Expects to Have Vaccines as Early as March 2021. Available online: https://www.cdc.gov.tw/En/Bulletin/Detail/ dyGaFbJOfhghSBgOEbH4Lg?typeid=158 (accessed on 19 February 2021).

10. World Health Organization Global Advisory Committee on Vaccine Safety, 27-28 May 2020. Available online: https: / /www.who. int/vaccine_safety/committee/reports/May_2020/en/ (accessed on 19 February 2021).

11. Malik, A.A.; McFadden, S.A.M.; Elharake, J.; Omer, S.B. Determinants of COVID-19 vaccine acceptance in the US. EClinicalMedicine 2020, 26, 100495. [CrossRef]

12. Lazarus, J.V.; Ratzan, S.C.; Palayew, A.; Gostin, L.O.; Larson, H.J.; Rabin, K.; Kimball, S.; El-Mohandes, A. A global survey of potential acceptance of a COVID-19 vaccine. Nat. Med. 2020, 4, 100044. [CrossRef] [PubMed]

13. Wouters, O.J.; Shadlen, K.C.; Salcher-Konrad, M.; Pollard, A.J.; Larson, H.J.; Teerawattananon, Y.; Jit, M. Challenges in ensuring global access to COVID-19 vaccines: Production, affordability, allocation, and deployment. Lancet 2021. [CrossRef]

14. Shahin, M.A.H.; Hussien, R.M. Risk perception regarding the COVID-19 outbreak among the general population: A comparative Middle East survey. Middle East Curr. Psychiatry 2020. [CrossRef]

15. Echoru, I.; Ajambo, P.D.; Bukenya, E.M. Acceptance and risk perception of COVID-19 vaccine in Uganda: A Cross sectional study in Western Uganda. BMC Public Health 2020. [CrossRef]

16. Janz, N.K.; Becker, M.H. The Health Belief Model: A Decade Later. Health Educ. Behav. 1984. [CrossRef]

17. Ajzen, I. The theory of planned behavior. Organ. Behav. Hum. Decis. Process. 1991. [CrossRef]

18. Huang, J.H.; Miao, Y.Y.; Kuo, P.C. Pandemic influenza H1N1 vaccination intention: Psychosocial determinants and implications from a national survey, Taiwan. Eur. J. Public Health 2012. [CrossRef]

19. Asnakew, Z.; Asrese, K.; Andualem, M. Community risk perception and compliance with preventive measures for covid-19 pandemic in Ethiopia. Risk Manag. Healthc. Policy 2020. [CrossRef]

20. Kwok, K.O.; Li, K.K.; Chan, H.H.H.; Yi, Y.Y.; Tang, A.; Wei, W.I.; Wong, S.Y.S. Community Responses during Early Phase of COVID-19 Epidemic, Hong Kong. Emerg. Infect. Dis. 2020, 26, 1575-1579. [CrossRef] [PubMed]

21. Dryhurst, S.; Schneider, C.R.; Kerr, J.; Freeman, A.L.J.; Recchia, G.; van der Bles, A.M.; Spiegelhalter, D.; van der Linden, S. Risk perceptions of COVID-19 around the world. J. Risk Res. 2020. [CrossRef]

22. Schwarzinger, M.; Watson, V.; Arwidson, P.; Alla, F.; Luchini, S. COVID-19 vaccine hesitancy in a representative working-age population in France: A survey experiment based on vaccine characteristics. Lancet Public Health 2021. [CrossRef]

23. Nichol, K.L.; Mac Donald, R.; Hauge, M. Factors associated with influenza and pneumococcal vaccination behavior among high-risk adults. J. Gen. Intern. Med. 1996. [CrossRef] [PubMed] 
24. MacDonald, N.E.; Eskola, J.; Liang, X.; Chaudhuri, M.; Dube, E.; Gellin, B.; Goldstein, S.; Larson, H.; Manzo, M.L.; Reingold, A.; et al. Vaccine hesitancy: Definition, scope and determinants. Vaccine 2015. [CrossRef] [PubMed]

25. Dodd, R.H.; Pickles, K.; Nickel, B.; Cvejic, E.; Ayre, J.; Batcup, C.; Bonner, C.; Copp, T.; Cornell, S.; Dakin, T.; et al. Concerns and motivations about COVID-19 vaccination. Lancet Infect. Dis. 2021, 21, 161. [CrossRef]

26. Tsai, F.J. Integrated Research Program on Ethics, Law, and Social Impact of Vaccine Development and Application: New and Under-Verified Public Policies and Social Awareness of Vaccine Introduction; Taipei, 2014. Available online: https://www.grb.gov.tw/search/ planDetail $\mathrm{id}=11273060 \&$ docId $=455873$ (accessed on 16 March 2021)

27. World Health Organization COVID-19: Vulnerable and High Risk Groups. Available online: https://www.who.int/ westernpacific/emergencies/covid-19/information/high-risk-groups\#: \{\}:text=COVID-19 (accessed on 19 February 2021).

28. World Health Organization WHO SAGE Roadmap For Prioritizing Uses Of COVID-19 Vaccines In The Context Of Limited Supply. Available online: https://www.who.int/publications/m/item/who-sage-roadmap-for-prioritizing-uses-of-covid-19 -vaccines-in-the-context-of-limited-supply (accessed on 19 February 2021).

29. Williams, L.; Gallant, A.J.; Rasmussen, S.; Brown Nicholls, L.A.; Cogan, N.; Deakin, K.; Young, D.; Flowers, P. Towards intervention development to increase the uptake of COVID-19 vaccination among those at high risk: Outlining evidence-based and theoretically informed future intervention content. Br. J. Health Psychol. 2020. [CrossRef]

30. Goldman, R.D.; Marneni, S.R.; Seiler, M.; Brown, J.C.; Klein, E.J.; Cotanda, C.P.; Gelernter, R.; Yan, T.D.; Hoeffe, J.; Davis, A.L.; et al. Caregivers' willingness to accept expedited vaccine research during the COVID-19 pandemic: A cross-sectional survey. Clin. Ther. 2020. [CrossRef]

31. Paul, E.; Steptoe, A.; Fancourt, D. Attitudes towards vaccines and intention to vaccinate against COVID-19: Implications for public health communications. Lancet Reg. Health Eur. 2021. [CrossRef] [PubMed]

32. Lucia, V.C.; Kelekar, A.; Afonso, N.M. COVID-19 vaccine hesitancy among medical students. J. Public Health 2020. [CrossRef]

33. Guidry, J.P.D.; Laestadius, L.I.; Vraga, E.K.; Miller, C.A.; Perrin, P.B.; Burton, C.W.; Ryan, M.; Fuemmeler, B.F.; Carlyle, K.E. Willingness to get the COVID-19 vaccine with and without emergency use authorization. Am. J. Infect. Control 2021. [CrossRef] [PubMed]

34. Bond, L.; Nolan, T. Making sense of perceptions of risk of diseases and vaccinations: A qualitative study combining models of health beliefs, decision-making and risk perception. BMC Public Health 2011. [CrossRef] [PubMed]

35. Sherman, S.M.; Smith, L.E.; Sim, J.; Amlôt, R.; Cutts, M.; Dasch, H.; Rubin, G.J.; Sevdalis, N. COVID-19 vaccination intention in the UK: Results from the COVID-19 vaccination acceptability study (CoVAccS), a nationally representative cross-sectional survey. Hum. Vaccines Immunother. 2020. [CrossRef]

36. Ozawa, S.; Stack, M.L. Public trust and vaccine acceptance-international perspectives. Hum. Vaccines Immunother. 2013, 9, 1774-1778. [CrossRef]

37. Larson, H.J.; Clarke, R.M.; Jarrett, C.; Eckersberger, E.; Levine, Z.; Schulz, W.S.; Paterson, P. Measuring trust in vaccination: A systematic review. Hum. Vaccines Immunother. 2018, 14, 1599-1609. [CrossRef] 